\title{
Organizational Design of Secondary Aviation / Aerospace / Engineering Career Education Programs
}

\author{
Susan Kelly Archer, Ph.D., Ed.D. ${ }^{1}$ \\ David Esser, Ph.D. ${ }^{2}$
}

\begin{abstract}
The goal of this study was to identify and evaluate the underlying organizational factors of successful secondary aviation/aerospace/engineering career education programs, through application of measures traditionally associated with organizational theory. Analysis methods included factor analysis, structural equation modeling, and a review of study participants' comments to identify emerging themes for triangulation with the statistical analysis results. Participants in the study comprised aviation/aerospace/engineering career education stakeholders. Hypothesis testing results suggested that the most important factor in predicting success for an aviation/aerospace/engineering program is personal motivation related to learning. Though other underlying factors, including leadership/collaborative environment, organizational accountability, and resource availability were clearly related to perceived program success, these relationships appeared to be indirect. The paired qualitative analysis of participant comments generated themes that transcended survey item topics. Personal motivation was the most commonly recurring theme in comments, supporting the hypothesis testing result indicating its predictive strength for an organization's success.
\end{abstract}

Keywords: career education, workforce development, aviation, aerospace, engineering.

\footnotetext{
${ }^{1}$ Adjunct Instructor, College of Arts \& Sciences, Worldwide Campus, Embry-Riddle Aeronautical University, 1 Aerospace Blvd. Daytona Beach, Florida, USA. Email: archers2@erau.edu

${ }^{2}$ Professor, College of Aviation, Daytona Campus, Embry-Riddle Aeronautical University, 1 Aerospace Blvd. Daytona Beach, Florida, USA. Email: esserd@erau.edu
} 


\section{INTRODUCTION}

Workforce needs for the aviation, aerospace, and engineering industries are projected to grow considerably over the next 20 years. The aviation industry projects a need for almost two and a half million new aircrew and maintenance employees to meet anticipated global demand (Boeing, 2019). The industry will also need engineers, aviation managers, and workers in other aviation and aerospace disciplines. The correlated supply of potential employees does not appear to be equivalent. It is imperative that quality career education programs in these three critical industries be expanded so that the demand for employees with the right academic backgrounds and practical skills can be met. While most research on educational programs focuses on student outcomes such as graduation rates or college acceptance, aviation/aerospace/engineering career education programs needed investigation at an organizational level to develop a model for sustainable success. Survey items associated with organizational design were modified to describe educational programs (Appendix 1). A combination of analysis methods: exploratory factor analysis (EFA), confirmatory factor analysis (CFA) and structural equation modeling (SEM) was applied to survey data collected from stakeholders in school-based and community-based programs. Results of the investigation defined underlying constructs associated with program success and described their interrelationships. The resulting model can be used by groups who are designing or improving secondary programs so that they can focus on developing sustainable successful organizations.

New research should continue the examination of career and technical education academies and programs but move beyond the traditional focus on school-based student outcomes such as attendance and dropout prevention, impact on grades and standardized test scores, or workforce readiness (Friedman et al., 2017; Hackmann, Malin, \& Ahn, 2018; Hackman, Malin, \& Gilley, 2018; Kreisman et al., 2019; Passarella, 2018). Though some recent research has focused on STEM programs (Finkel, 2016; Icel, 2018; Mohtar et al., 2019; Turner et al., 2016), these studies continued to concentrate on student outcomes with only a few (Kiliçoğlu et al., 2019; Thiry et al., 2017) investigations of educational programs at the organizational level. Recent congressional testimony (Lang, 2020) reflected current forecasts of significant aviation workforce needs, with related requirements for development of education pathways prior to high school graduation. Such pathways should be designed with dual focus on expansion of positive student outcomes and development of research-based, sustainable organizational structures.

Robledo (2013) suggested that theory-based evaluation of an organization should include an integration of ideas from each of the four quadrants of the All-Quadrants-All-Levels model. The following theories were selected for use in developing the survey instrument: Motivational Theory of Modern Expectancy-Value; Organizational Development Theory; High Performance Culture Theory; and Theory of Organizational Excellence (Figure 1). Descriptors extracted from the theoretical foundation for each of the individual theories included in the model were used to develop the survey items (Table 1). 


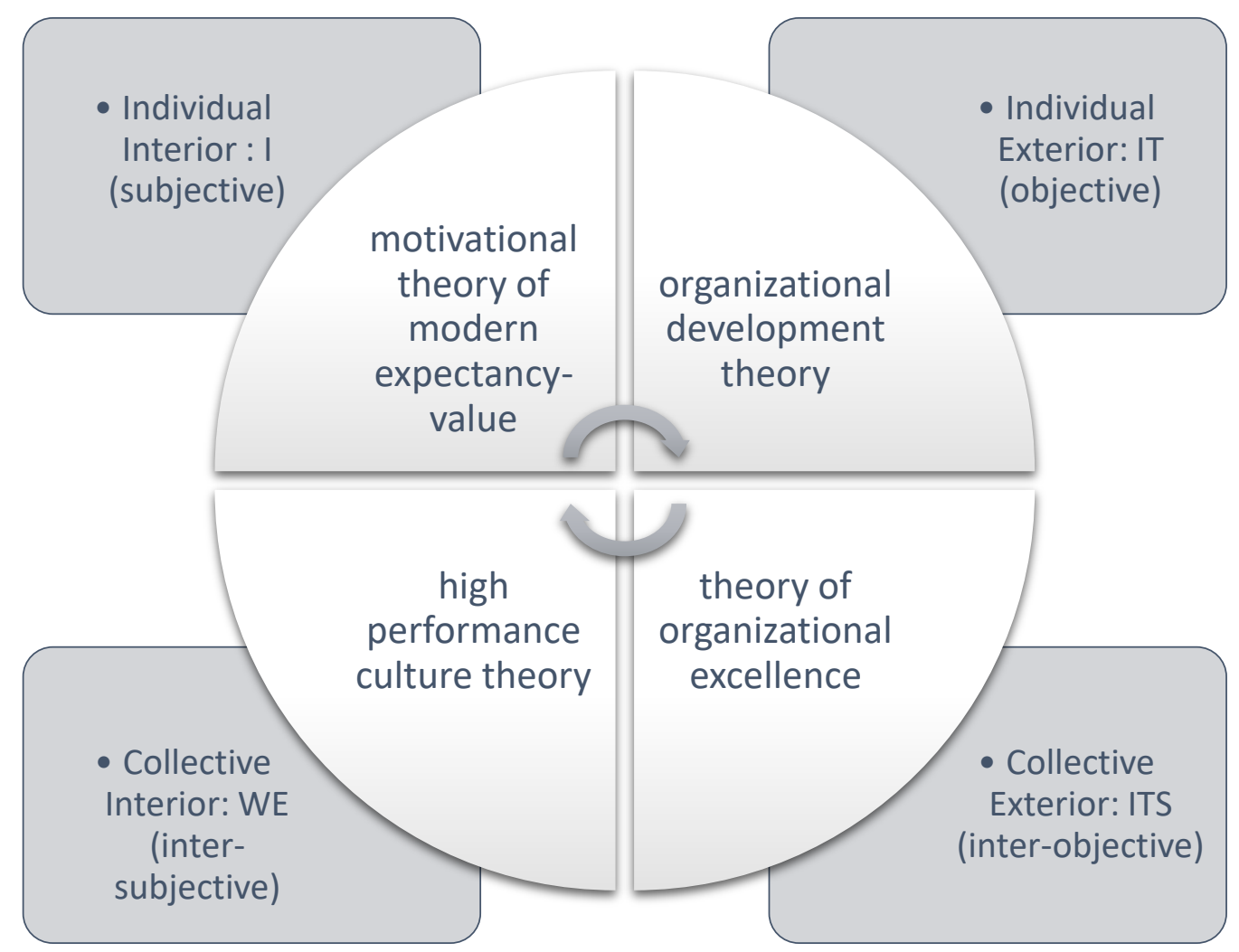

Figure 1: Theoretical Frameworks Model for Studying Organizational Design using AQAL Model

Note. Adapted from "An all-inclusive framework for the $21^{\text {st }}$ century: An overview of integral theory" by S. Esbjorn-Hargens (2009 Mar 12), in IntegralPost: Transmissions from the Leading Edge [Webpage]. Retrieved from http://integrallife.com/integral-post/overview-integral-theory. Copyright 2009 by IntegralPost. 
Table 1: Descriptors Used to Develop Survey Items

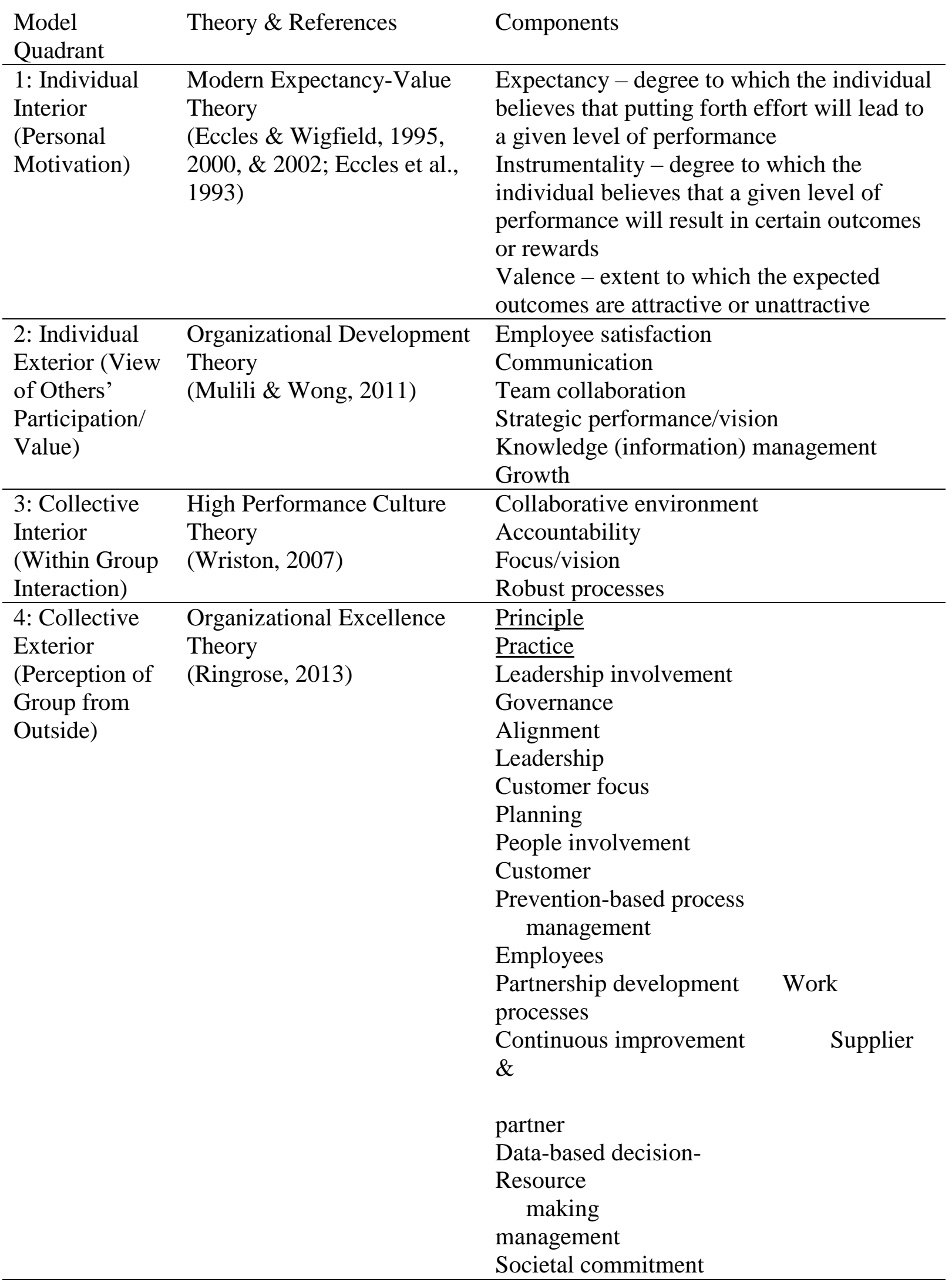




\section{METHODOLOGY}

A mixed-methods approach to data analysis, involving both statistical analysis of Likert-scale survey items and phenomenological examination of additional comments made by study participants, allowed for a comprehensive understanding of the amassed information. Initial exploration of survey item responses via frequency tables and bar graphs identified survey items that might prove problematic in further data analysis and hypothesis testing phases. We used EFA to identify underlying factors associated with success that were represented by correlated survey items. The second step, CFA involved evaluating the measurement model that represented relationships between survey items and underlying factors. After further refinement of the measurement model, we used SEM to analyze the structural model for interrelationships between factors, and then a subsequent post hoc analysis to investigate the possibility of generating a better-fitting model for the data. A simultaneous qualitative analysis involved examining trends in participant comments to identify underlying themes across multiple items.

\section{RESULTS}

\subsection{Descriptive Analysis}

The initial descriptive statistics review of survey item responses suggested generally positive attitudes toward academies/programs, with items written as positive statements showing the highest frequencies in responses of agree or strongly agree. Most items written as negative statements showed the highest frequencies in responses of disagree or strongly disagree, indicating positive sentiments related to the participant's program. However, three items written as negative statements produced a wider variability in survey responses. The survey item with the most unexpected responses was item 15 . The expectation was that a majority of participants would disagree with this statement, however, the opposite occurred. Half of all participants chose either agree or strongly agree as their response. There was also an unexpected trend in responses for item 20. Though the highest frequency was associated with the expected choice of disagree (34.6\%), almost the same proportion (33.7\%) chose either agree or strongly agree. This phenomenon occurred once more with item 24 . The highest frequency was associated with the expected choice of disagree (36\%), but $30.9 \%$ selected agree or strongly agree. It may be important to note that the only three survey items that produced unexpected results were all items written in a negative format. Additionally, the variability in these responses may have influenced some of the statistical results in hypothesis testing.

\subsection{Exploratory Factor Analysis}

Although there were three items that generated unexpected and potentially anomalous responses, we included all survey items associated in the literature with predictors of organizational success in the first phase of data analysis, EFA. Initial evaluation of the interitem correlation matrix to verify EFA assumptions led to elimination of item 15, which had been flagged during the descriptive analysis as potentially problematic. 
Application of the EFA procedure led to further reduction in the number of survey items to generate the optimal model. This phase involved principal component analysis (PCA) and Oblimin rotation, applying the Kaiser-1 criterion (a cut-off eigenvalue of 1.00 for identifying factors) and scree plot exploration for factor extraction (Lattin et al., 2003). The initial EFA with no assumptions about the number of factors resulted in identification of five factors. The scree plot appeared to have elbows at three and five factors, the latter supporting the eigenvalue - based results (Figure 2). Almost 54\% of the variance was accounted for in the first five factors (Table 2). Subsequent EFA iterations, involving an Oblimin Promax rotation, led to removing survey items 12,14 , and 18 ; these items did not meet minimum the factor loading threshold. Upon making these changes, the number of underlying factors was reduced to four.

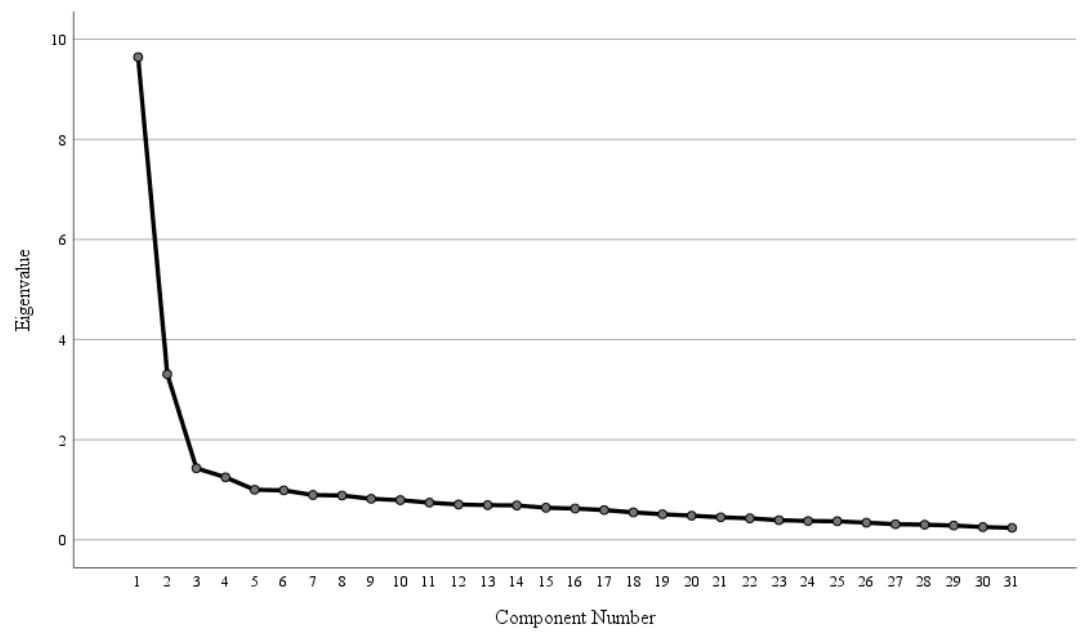

Figure 2: Scree Plot Showing Elbows (inflection points) at Three and Five Factors

\section{Table 2: Excerpt of Total Variance Explained Showing EFA Results Based on Eigenvalues}

\begin{tabular}{|c|c|c|c|c|c|c|}
\hline \multicolumn{7}{|c|}{ Total Variance Explained } \\
\hline \multirow[b]{2}{*}{ Component } & \multirow[b]{2}{*}{ Total } & \multicolumn{2}{|c|}{ Initial Eigenvalues } & \multicolumn{3}{|c|}{ Extraction Sums of Squared Loadings } \\
\hline & & $\%$ of Variance & Cumulative $\%$ & Total & $\%$ of Variance & Cumulative $\%$ \\
\hline 1 & 9.642 & 31.104 & 31.104 & 9.642 & 31.104 & 31.104 \\
\hline 2 & 3.309 & 10.673 & 41.777 & 3.309 & 10.673 & 41.777 \\
\hline 3 & 1.430 & 4.614 & 46.392 & 1.430 & 4.614 & 46.392 \\
\hline 4 & 1.248 & 4.027 & 50.418 & 1.248 & 4.027 & 50.418 \\
\hline 5 & 1.001 & 3.230 & 53.648 & 1.001 & 3.230 & 53.648 \\
\hline 6 & .988 & 3.187 & 56.835 & & & \\
\hline 7 & .896 & 2.891 & 59.726 & & & \\
\hline
\end{tabular}


We examined the survey items associated with each of the factors, leading to factor classification as leadership and collaborative environment, motivation and learning, organizational accountability, and resource availability. Relationships between survey items and these factors were reflected in the measurement model (Figure 3). Our review of the extant literature related to these constructs resulted in development of three research questions with associated sets of hypotheses (regression coefficients represented by $\beta$ ), and the structural model (Figure 4).

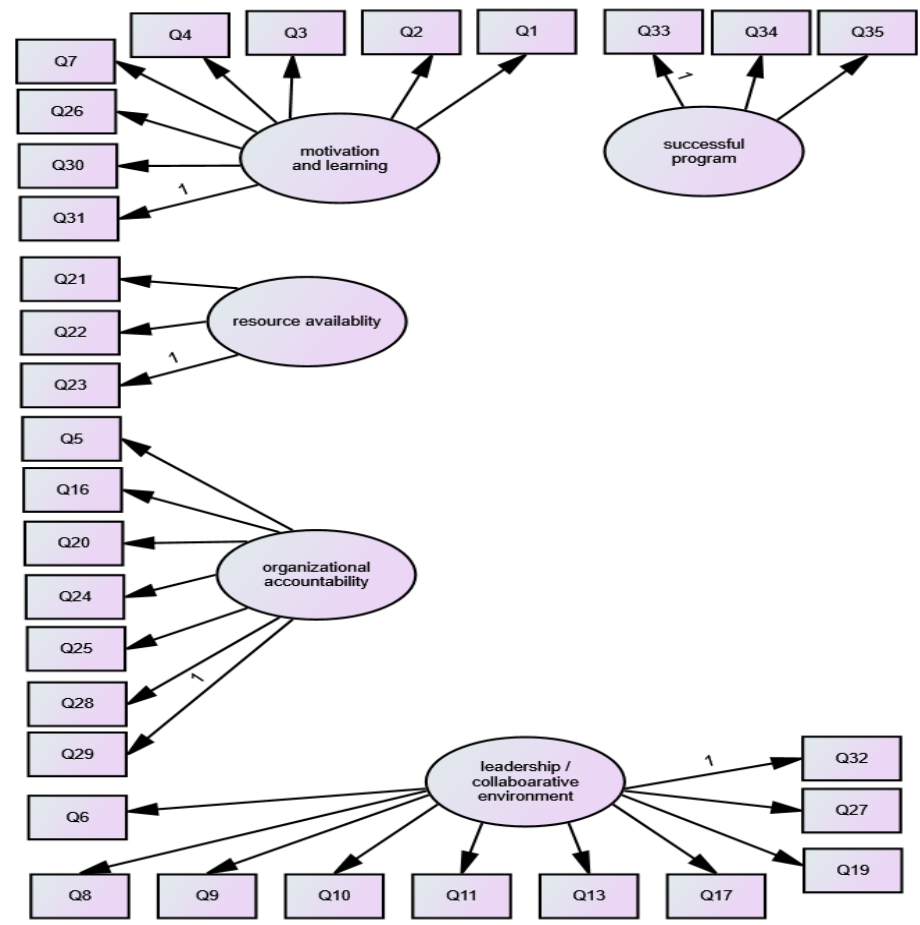

Figure 3: Measurement Model for CFA Based on Results of EFA 


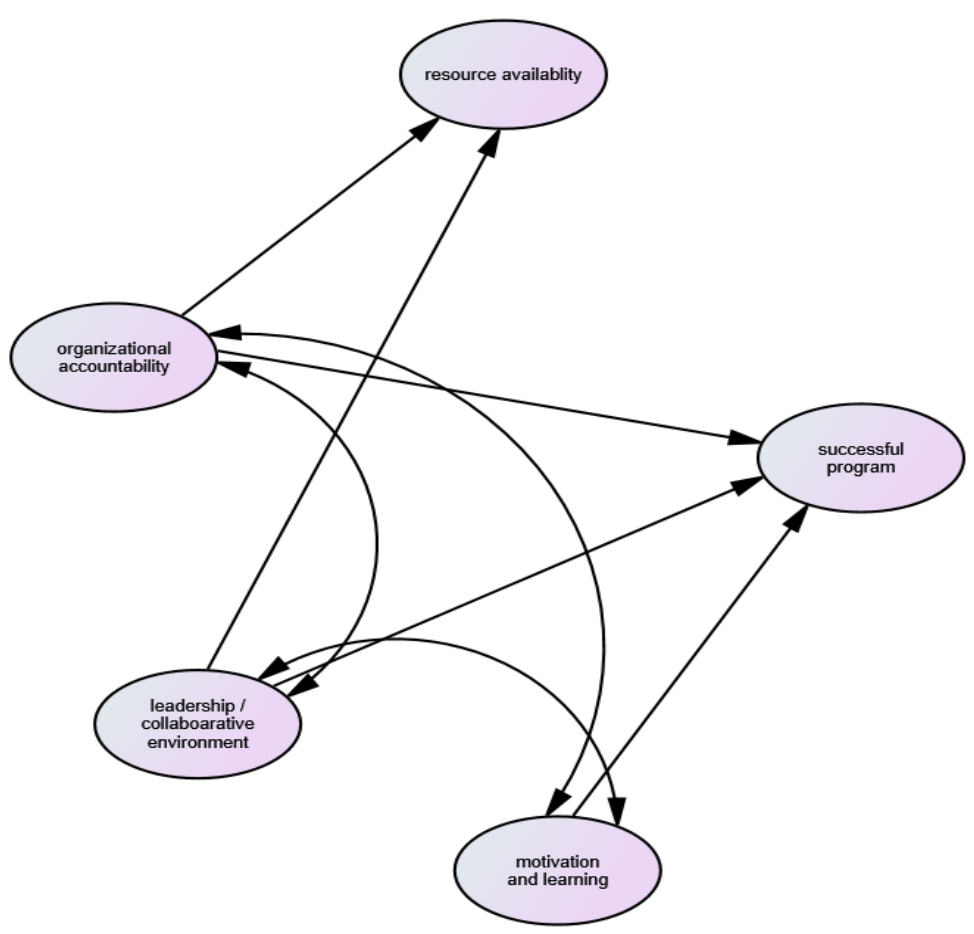

Figure 4: Structural model based on results of EFA

Research Question 1: Is the endogenous variable success predicted by the three exogenous variables (motivation and learning, leadership/collaborative environment, organizational accountability)?

$\mathrm{H}_{110}: \beta$ for the exogenous variable motivation and learning $=0$.

$\mathrm{H}_{11 a}: \beta$ for the exogenous variable motivation and learning $>0$.

$\mathrm{H}_{120}$ : $\beta$ for the exogenous variable leadership/collaborative environment $=0$.

$\mathrm{H}_{12 a}: \beta$ for the exogenous variable leadership/collaborative environment $>0$.

$\mathrm{H}_{130}: \beta$ for the exogenous variable organizational accountability $=0$.

$\mathrm{H}_{13 a}: \beta$ for the exogenous variable organizational accountability $>0$.

Research Question 2: Is the endogenous variable resource availability predicted by the two exogenous variables (leadership/collaborative environment, organizational accountability)?

$\mathrm{H}_{210}$ : $\beta$ for leadership/collaborative environment relating to resource availability $=0$.

$\mathrm{H}_{21 a}: \beta$ for leadership/collaborative environment relating to resource availability $>0$.

$\mathrm{H}_{220}$ : $\beta$ for organizational accountability relating to resource availability $=0$.

$\mathrm{H}_{22 a}: \beta$ for organizational accountability relating to resource availability $>0$.

Research Question 3: Is there a model that better fits the data than the original structural equation model?

$\mathrm{H}_{30}$ : The original model provides the best fit for the sample data. 
$\mathrm{H}_{3 a}$ : There is at least one post hoc model that is a better fit for the sample data.

\subsection{Confirmatory Factor Analysis}

The second phase of data analysis involved CFA. Examination of the regression coefficients for the survey items identified in the measurement model (Figure 3), revealed that all of the coefficients were significant ( $p$-values $<0.001)$. Although all regression coefficients were significant, a review of GoF indices suggested the measurement model required some modification to be classified as good fitting $\left(X^{2}=878.866\right.$ with $d f=426$ and $p$-value $<0.001$, $\mathrm{CFI}=0.893$, RMSEA $=0.055$, SRMR $=0.0624$, PNFI $=0.745)$. The values for RMSEA, SRMR, and PNFI were within the acceptable range (RMSEA $<0.08$; SRMR $<0.08$, PNFI > 0.50), however, the CFI was low (references indicate a minimum value of 0.90 should be achieved).

Adjustments based on modification indices (MI) produced as part of the CFA resulted in improved fit indices. These adjustments included adding covariances between error terms for four pairs of survey items: 20 and 24; 27 and 32; 4 and 7; and 9 and 32. These covariances showed connections between perceptions of how decisions were being made within academies/programs, perceptions of personal and organizational continuous improvement, decision-making and program activities, and collaborative leadership leading to organizational improvement. Table 3 shows the overall change to GoF indices after adding these covariances.

Table 3: Changes to Goodness of Fit Indices

\begin{tabular}{cccccccc}
\hline Description & $X^{2}$ & $d f$ & $p$-value & CFI & RMSEA & SRMR & PNFI \\
\hline $\begin{array}{c}\text { original } \\
\text { measurement } \\
\text { model } \\
\text { after }\end{array}$ & 878.866 & 426 & $<0.001$ & 0.893 & 0.055 & 0.0624 & 0.745 \\
$\begin{array}{c}\text { addition of } \\
\text { covariances }\end{array}$ & 804.830 & 422 & $<0.001$ & 0.910 & 0.051 & 0.0603 & 0.753 \\
\hline
\end{tabular}

\subsection{Reliability and validity of constructs}

Convergent and discriminant validity and construct reliability calculations revealed the need to remove some survey items to achieve or approach acceptable statistics. Items whose removal would make the most significant difference in evaluation statistics were reviewed to minimize the effect of the loss of information associated with said items. In each case, wording of the item being removed appeared closely related to other items associated with the same factor, thus its removal was not likely to eliminate important information from the study. Additionally, since all of the participant comments were retained for the qualitative analysis, there would still be some part of the responses for each of these removed items included in the final discussion and conclusions. Three items were removed and evaluation statistics recalculated, resulting in a final set of evaluation statistics that reflected validity and reliability improvement (Table 4). 
Table 4: Measurement Model Evaluation for Validity and Reliability

\begin{tabular}{|c|c|c|c|c|c|c|c|c|c|c|c|}
\hline Descr & $X^{2}$ & $d f$ & $\begin{array}{c}p- \\
\text { value }\end{array}$ & CFI & RMSEA & SRMR & PNFI & loadings & $\mathrm{CR}$ & AVE & $\begin{array}{c}\text { AVE > } \\
\text { MSV }\end{array}$ \\
\hline $\begin{array}{c}\text { model } \\
\text { with all } \\
\text { co- } \\
\text { variances }\end{array}$ & 804.83 & 422 & $\begin{array}{c}< \\
0.001\end{array}$ & 0.910 & 0.051 & 0.0603 & 0.753 & $\begin{array}{c}>0.5 \\
\text { except } \\
\text { Q23 } \\
(0.494)\end{array}$ & $\begin{array}{c}\text { all } \\
>0.7\end{array}$ & $\begin{array}{c}\text { lead collab } \\
0.38 \\
\text { org acc } 0.43 \\
\text { res avail } \\
0.53 \\
\text { motiv } \\
0.39 \\
\text { success } 0.46\end{array}$ & $\begin{array}{c}\text { only res } \\
\text { avail \& } \\
\text { org acc }> \\
\text { both msv; } \\
\text { lead } \\
\text { collab and } \\
\text { motiv } \\
\text { each }>2 \\
\text { of } 3\end{array}$ \\
\hline $\begin{array}{c}\text { removed } \\
\text { Q11, } \\
\text { Q26, Q6 }\end{array}$ & 660.40 & 338 & $\begin{array}{c}< \\
0.001\end{array}$ & 0.917 & 0.052 & 0.0605 & 0.755 & $\begin{array}{c}>0.5 \\
\text { except } \\
\text { Q23 } \\
(0.494)\end{array}$ & $\begin{array}{c}\text { all } \\
>0.7\end{array}$ & $\begin{array}{c}\text { lead collab } \\
0.40 \\
\text { org acc } 0.43 \\
\text { res avail } \\
0.53 \\
\text { motiv } 0.40 \\
\text { success } 0.46\end{array}$ & $\begin{array}{c}\text { only res } \\
\text { avail \& } \\
\text { org acc }> \\
\text { both } \\
\text { MSV; } \\
\text { lead } \\
\text { collab and } \\
\text { motiv } \\
\text { each > } 2 \\
\text { of } 3\end{array}$ \\
\hline
\end{tabular}

After removing three survey items, most of the indicators for model reliability and validity had improved. All factors had construct reliability (CR) values greater than the 0.7 threshold, suggesting the measurement model had high CR. All factor loadings except for the loading for one survey item related to resource availability (0.494) were greater than 0.5 , indicating adequate convergent validity. The survey item with a slightly lower factor loading was left in the model so that resource availability would have three indicators (meeting the threeindicator rule described by Hair et al. (2010)), as its loading was close to the 0.5 threshold. The average variance extracted (AVE) value for resource availability was greater than the advised threshold of 0.5 , suggesting adequate convergence. However, the remaining factors produced AVE values from 0.40 to 0.46 . Though these values were not greater than the ruleof-thumb threshold, they were either close ( 0.43 for organizational accountability and 0.46 for successful program) or had improved with removal of low-performing survey items (leadership/ collaborative environment improved from 0.38 to 0.40 and motivation/learning improved from 0.39 to 0.40 ). At this point, removing any more survey items would exceed the recommended maximum of $20 \%$ (Hair et al., 2010) and would likely lead to the loss of information important to the analysis, so it was noted that one convergent validity measure (factor loadings) indicated convergence for all factors except resource availability, while a second measure (AVE) indicated convergence for resource availability.

Discriminant validity was assessed by comparing AVE values for pairs of factors to their combined maximum squared variance (MSV). Only resource availability (AVE $=0.53>$ MSVs of $0.40,0.33$, and 0.02) and organizational accountability (AVE $=0.43>$ MSVs of $0.02,0.10$, and 0.22 ) had high discriminant validity. Leadership/collaborative environment $(\mathrm{AVE}=0.40>\mathrm{MSVs}$ of 0.33 - resource availability and 0.10 - organizational accountability; AVE $=0.40<\mathrm{MSV}$ of 0.73 - motivation and learning) showed partial discriminant validity. The same held true for motivation and learning (AVE $=0.404>\mathrm{MSVs}$ 
of 0.21 - organizational accountability and 0.403 - resource availability; AVE $=0.404<0.73$ - leadership/collaborative environment) showing partial discriminant validity. Two factors (leadership/collaborative environment and motivation and learning) were truly distinct from both resource availability and organizational accountability but were not distinct from each other. Thus, the measurement model met the criteria to be classified as an adequate to goodfitting model and met some of the criteria to be classified as having high construct reliability and adequate construct validity (some high, some low).

\subsection{Hypothesis Testing Results}

After final modifications to the measurement model, we evaluated the structural model. The first step involved review of the regression coefficients for the latent constructs, to evaluate research questions one and two. The parameter estimates for leadership/collaborative environment and organizational accountability as predictors for success were not significant ( $p$-value $=0.356$ and $p$-value $=0.758$, respectively). Additionally, the parameter estimate for organizational accountability as a predictor for resource availability was not significant ( $p$ value $=0.474$ ). Given that the parameter estimates for leadership/collaborative environment as a predictor for success and organizational accountability as a predictor for resource availability were negative, these relationships were removed from the model, and it was run again. The parameter estimate for organizational accountability as a predictor for success continued to be insignificant $(0.037$ with $p$-value $=0.383)$, so it was subsequently removed. The remaining parameter estimates were significant (Table 5). Thus, there was sufficient evidence to reject $\mathrm{H}_{110}$, but not $\mathrm{H}_{120}$ nor $\mathrm{H}_{130}$. There was also sufficient evidence to reject $\mathrm{H}_{210}$, but not $\mathrm{H}_{220}$. It should be noted that when the related modifications were made to the model, variance terms for both the endogenous variables success and resource availability were significant ( 0.035 with $p$-value $=0.023$ and 0.157 with $p$-value $<0.001$, respectively).

Table 5: Final Regression Coefficient Estimates for Latent Constructs

\begin{tabular}{lrlrrrr}
\hline & & & Estimate & S.E. & C.R. & P \\
\hline successful_program & $\leftarrow-$ & motivation_learning & .967 & .093 & 10.405 & $* * *$ \\
resource_availability & $\leftarrow-$ & leadership_collab_envir & .640 & .098 & 6.509 & $* * *$ \\
\hline
\end{tabular}

After evaluating the regression coefficient estimates for the structural model, the covariances between latent constructs were examined. All of the estimated covariances were significant with $p$-values $<0.001$. The GoF indices for this model were reviewed and are compared to the initial structural model in Table 6. Though there were slight increases in the SRMR, it was still less than the 0.80 threshold. Additionally, the PNFI increased (due to the reduction in estimated parameters), indicating a better-fitting model. 
Table 6: Goodness of Fit Indices for Structural Model

\begin{tabular}{cccccccc}
\hline Model & $X^{2}$ & $d f$ & $p$-value & CFI & RMSEA & SRMR & PNFI \\
\hline initial & 660.40 & 338 & $<0.001$ & 0.917 & 0.052 & 0.0605 & 0.755 \\
$\begin{array}{c}\text { after } \\
\text { removal of } \\
\begin{array}{c}\text { insignificant } \\
\text { parameters }\end{array}\end{array}$ & 662.60 & 341 & $<0.001$ & 0.917 & 0.052 & 0.0606 & 0.761 \\
\hline
\end{tabular}

The final research question focused on the possibility that post hoc analysis might produce a better fitting model. Multiple models were designed reflecting modifications to predictor and covariant relationships. One resulting model produced the best set of GoF indices, with only a slight decrease in PNFI as compared to the first structural model with all parameter estimates significant (Table 7). No subsequent modifications produced models with equivalent or better GoF measurements. I classified this model as the best fitting model for the collected data, providing sufficient evidence to reject $\mathrm{H}_{30}$. The final model with regression, variance, and covariance estimates is shown in Figure 5 (see Appendix 2).

Table 7: Goodness of Fit Indices for Post Hoc Structural Model

\begin{tabular}{cccccccc}
\hline Model & $X^{2}$ & $d f$ & $p$-value & CFI & RMSEA & SRMR & PNFI \\
\hline $\begin{array}{c}\text { after removal } \\
\text { of } \\
\begin{array}{c}\text { insignificant } \\
\text { parameters }\end{array}\end{array}$ & 662.60 & 341 & $<0.001$ & 0.917 & 0.052 & 0.0606 & 0.761 \\
$\begin{array}{c}\text { new model } \\
\text { with } \\
\text { modifications } \\
\text { to latent } \\
\text { construct } \\
\text { relationships }\end{array}$ & 645.910 & 339 & $<0.001$ & 0.921 & 0.051 & 0.0590 & 0.760 \\
\hline
\end{tabular}




\section{CONCLUSIONS}

The hypothesis testing results suggested that the most important factor in predicting success for an aviation/aerospace/engineering academy or program is personal motivation related to learning. Though other underlying factors were clearly related to perceived program success, they appeared to have indirect relationships with success. The construct associated with resources focused more on availability than on management, which was even more clearly defined in additional comments by participants.

Perhaps one of the important conclusions that can be drawn from the results is that success of a learning organization is directly related to personal motivation of its stakeholders, and that motivation can be impacted by interrelated combinations of constructs identified in the literature associated with the theoretical frameworks related to organizational design and excellence. Other factors drawn from the literature on organizational design that appear to have a direct relationship with motivation and learning and, by extension, an indirect relationship with program success are leadership/collaborative environment, organizational accountability, and resource availability.

Motivation was the most commonly recurring theme in participants' additional comments, indicating its predictive strength for an organization's success. Emerging themes of collaboration, vision / alignment, and concerns regarding limited resources and funding, are directly associated with the remaining three exogenous variables (leadership/collaborative environment, organizational accountability, and resource availability, respectively) in the final model. A theme of communication could be associated with collaboration in the final model. The identification of, and association between, these underlying constructs should add to the body of research on organizational design, focusing on educational or learning organizations and specifically concentrating on career education programs with aviation, aerospace, and/or engineering themes.

The results of this research study can provide a guide for stakeholders interested in designing a new aviation/aerospace/engineering career education academy or program. Participant comments, written in a general manner, would enhance such a guide with ideas for components of a successful program and possible pitfalls to avoid. However, as the survey and comment results indicated in this study, personal motivation is the most important factor in creating a successful program. Thus, it would be imperative to develop as deep an understanding as possible of the potential population for a new program as an early step in design, so that individuals would be motivated to join the program, stay with it, and become productive stakeholders themselves.

Because survey participants self-selected, this study was based on voluntary response data which can lack generalizability to the population. There were "no opinion" responses to individual survey items, but it is difficult to determine if an individual chose "no opinion" because they truly had no opinion or because they had a neutral opinion. It is also impossible to estimate the opinions of academy and program stakeholders who were invited but chose 
not to participate in the study. It is possible that stakeholders in academies or programs that were not identified for the study would have opinions that differ significantly from those offered by the individuals who did participate in the study.

Missing information created a further limitation. Because Likert-scale items are ordinal data, it is generally considered inappropriate to impute values for missing data. The EFA procedure ignores all data for a case that has a missing value for any individual variable. For this reason, all cases that had missing data were removed from the data set before any analysis was performed. It is possible that information pertinent to hypothesis testing was lost in the removal of these cases. To mitigate the loss of information, all comments by these participants were retained for qualitative review.

A recommendation related to the target population is that the research be replicated with a homogeneous sample of stakeholders in high school academies only. This sample could include stakeholders from various regions within the United States as well as regions around the world, to identify global trends as well as significant global differences. A very large sample would allow for subgroups to be evaluated.

Given the result that personal motivation was the most closely related construct to program success, researchers should expand study of stakeholder motivation. Considering the realities of increased aviation/aerospace/engineering workforce demands and continued disparity between population demographics and workforce pipeline demographics for these three industries, it is evident that research should involve questions of what motivates students (especially those in traditionally underrepresented demographic subgroups) to become and remain involved in aviation/aerospace/engineering career education academies/programs. To facilitate deeper understanding of program faculty and staff motivation, research should involve investigating instructional training and experience as well as "the why" associated with a desire to work in these career education programs. Subsequent study of individuals who are employed in these industries should investigate what, if any, secondary career education opportunities they may have participated in and how those opportunities shaped their learning as well as their personal career trajectories.

\section{ACKNOWLEDGMENTS}

We would like to thank the members of the dissertation review committee, Dr. Michael Wiggins (Embry-Riddle Aeronautical University), Dr. Soumia Ichoua (University of Virginia Health System), and Dr. Thomas Serwatka (University of North Florida, emeritus) for their expert advice and project review.

\section{REFERENCES}

Boeing. (2019). Commercial: About our market: Pilot \& technician outlook. Retrieved from https://www.boeing.com/commercial/market/pilot-technician-outlook/ 
Eccles, J. S., \& Wigfield, A. (1995). In the mind of the achiever: The structure of adolescents' academic achievement related-beliefs and self-perceptions. Personality and Social Psychology Bulletin, 21, 215225.

Eccles, J. S., \& Wigfield, A. (2000). Expectancy-value theory of achievement motivation. Contemporary Educational Psychology, 25, 68-81.

Eccles, J. S., \& Wigfield, A. (2002). Motivational beliefs, values, and goals. Annual Review of Psychology, 53, $109-132$.

Eccles, J. S., Wigfield, A., Harold, R., \& Blumenfeld, P. B. (1993). Age and gender differences in children's self- and task perception during elementary school. Child Development, 64, 830-847.

Esbjorn-Hargens, S. (2009, Mar 12). An all-inclusive framework for the $21^{\text {st }}$ century: An overview of integral theory, IntegralPost: Transmissions from the Leading Edge.

Finkel, L. (2017). Walking the path together form high school to STEM majors and Careers: Utilizing community engagement and a focus on teaching to increase opportunities for URM students. Journal of Science and Educational Technology, 26.

Friedman, A. D., Melendez, C. R., Bush, A. A., Lai, S. K., \& McLaughlin, J. E. (2017). The young innovators program at the Eshelman Institute for Innovation: A case study examining the role of a professional pharmacy school in enhancing STEM pursuits among secondary school students. International Journal of STEM Education, 4(17), 1-7. https://doi.org/10.1186/s40594-017-0081-4

Hackmann, D. G., Malin, J. R., \& Ahn, J. (2019). Data use within education-centered cross-sector collaboration. Journal of Educational Administration, 57(2), 118-133. https://doi.org/10.1108/JEA-08-2018-150

Hackmann, D. G., Malin, J. R., \& Gilley, D. (2018). Career academies: Effective structures to promote college and career readiness. The Clearing House: A Journal of Educational Strategies, Issues and Ideas, 91, 4-5, 180-185. $\quad$ https://doi.org/10.1080/00098655.2018.1480196

Hair, J. F., Black, W. C., Babin, B. J., \& Anderson, R. E. (2010). Multivariate data analysis. Prentice Hall.

Icel, M. (2018). Implementation of STEM policy: A case study of a STEM-focused urban charter school. Journal of STEM Education, 19(3), 7-13.

Kiliçoğlu, G., Yilmaz Kiliçoğlu, D., \& Karadağ, E. (2019). Do schools fail to “Walk their talk?” Development and validation of a scale measuring organizational hypocrisy. Leadership and Policy in Schools, 18(1), 5282.

Kreisman, D., \& Stange, K. (2019). Depth over breadth. Education Next; Cambridge, 19(4), 1-7.

Lang, K. (2020). Looking forward: The future of America's aviation maintenance and manufacturing workforce: Hearings before the Committee on Transportation and Infrastructure Subcommittee

on Aviation, House of Representatives, $115^{\text {th }}$ Cong. (2020).

Lattin, J., Carroll, J. D., \& Green, P. E. (2003). Analyzing multivariate data. Brooks/Cole -Thomson Learning.

Mohtar, L. E., Halim, L., Abd Rahman, N., Maat, S. M., Iksan, Z. H., \& Osman, K. (2019). A model of interest in STEM careers among secondary school students. Journal of Baltic Science Education, 18(3), 404416. https://doi.org/10.33225/jbse/19.18.404

Mulili, B. M., \& Wong, P. (2011). Continuous organizational development. Industrial and Commercial Training, 43(6), 377-384.

Passarella, A. (2018). The necessary components of an effective career and technical education (CTE) program. Policy Brief. Johns Hopkins School of Education.

Ringrose, D. (2013). Development of an organizational excellence framework. The TQM Journal, 25(4), 441452.

Robledo, M. A. (2013). Integrating management theory. Journal of Integral Theory and Practice, 8(1\&2), 5770 .

Thiry, H., Archie, T., Arreola-Pena, M., \& Laursen, S. (2017). Linkages between youth diversity and organizational and program characteristics of out-of-school-time science programs: A mixed-methods study. International Journal of Science Education, Part B, 7(2), 121-145. https://doi.org/10.1080/21548455.2015.1105397

Turner, M., Dues, J., Cooley, T., Webster, R., Kopp, R., McCart, A., \& Reynolds, D. (2016). Purdue mission to Mars: Recruiting high school students into a polytechnic college. Journal of Engineering Technology, 8-17. Wriston, M. J. (2007). Creating a high-performance culture. Organization Development Journal, 25(1), 8-16. 


\section{Appendix 1: Survey Items}

1. I believe that I can be successful as a participant in and/or contributor to my academy/ program.

2. I believe my effort/participation level with respect to my program directly affects how well I achieve my expectations.

3. I believe that participating in and/or contributing to my program is a valuable experience (with respect to my personal goals).

4. Decisions about my program are aligned with the vision statement.

5. Daily activities/processes within my program are not aligned with the vision statement.

6. There is a system in place to measure my program's progress according to our vision statement.

7. The things I participate in that are related to my program seem to be aligned with the vision statement.

8. Leaders (students and/or adults) help everyone work to achieve the goals and objectives of my program.

9. Leaders (students and/or adults) regularly interact with members of my program to involve us in planning and decisions.

10. Everyone involved with my program (students and/or adults) is expected to contribute to the program's success.

11. When someone involved with my program (students and/or adults) does not meet their responsibilities, they know they will be held accountable.

12. Decisions about my program are made by the people who have the best information available.

13. Important information about my program is communicated to everyone in a timely manner.

14. When I have a question or concern about my program, I can get answers or responses quickly.

15. In my program, there are specific groups of people (e.g., seniors who have been in the program for four years, or math teachers) have better access to information we all need.

16. The way information is presented for my program makes it difficult to understand.

17. We use teamwork to get work done in my program.

18. People who have different skills, knowledge, or talents, work together to make the best decisions for my program.

19. Everyone involved with my program (students and/or adults) is able to have input about what we do and the direction we are going.

20. In my program we have power struggles that affect how well we achieve our goals and objectives.

21. We have the supplies and material resources we need to meet the goals and objectives of my program.

22. We have the technology and equipment resources we need to meet the goals and objectives of my program.

23. We have the people (students and/or adults) we need to meet the goals and objectives of my program.

24. Resources are not always used for activities that align with the program vision. 
25. It is difficult to determine who makes decisions about how to use resources for my program.

26. My program provides opportunities for me to improve my related skills, knowledge, or talents, if I want to participate.

27. Everyone (students and/or adults) in my program is involved in lifelong learning to increase their related skills, knowledge, or talents.

28. My program does not provide a support system for helping participants meet their responsibilities.

29. I believe I can learn more career-related knowledge associated with my program outside the program than by participating within it.

30. My program is flexible enough to adapt to change in related industries or academic requirements.

31. I believe my program gets better (with respect to the vision statement, goals, and objectives) every year.

32. I believe everyone involved with my program (students and/or adults) plays a part in making my program better (with respect to the vision statement, goals, and objectives).

33. I believe my program is a successful organization.

34. My program is recognized as successful by others through awards, public media (newspaper, online, or television reports of achievement), or other methods. (Please specify the 'other' method in the Comment box).

35. I would recommend my program to students/colleagues who I know, who are interested in aviation/aerospace/engineering education and/or careers. 


\section{Appendix 2: Final Model with Parameter Estimates}

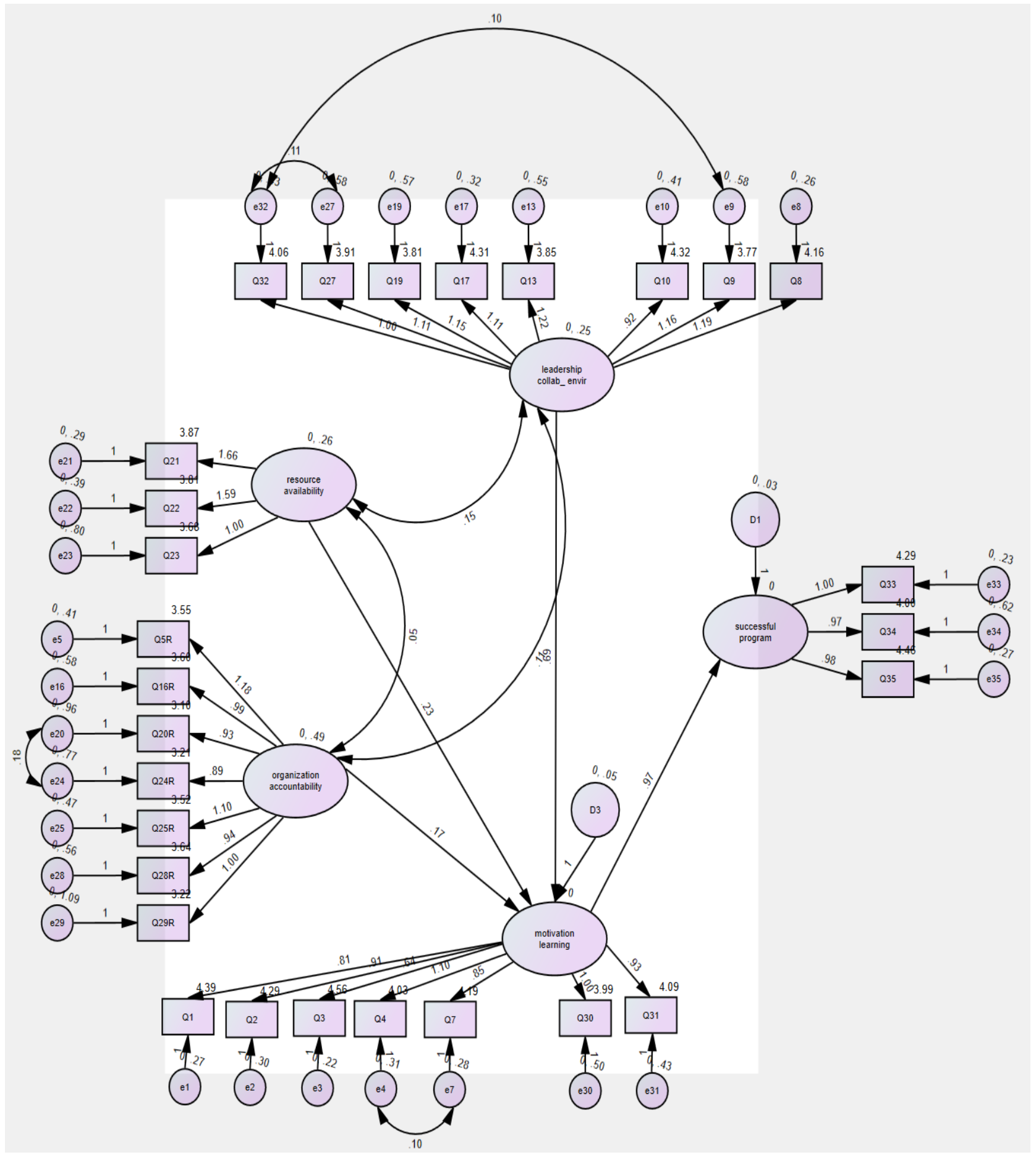

Figure 5: Final Model with Parameter Estimates 